\title{
The ontological implications of neo-Fregeanism
}

\author{
Las implicaciones ontológicas del neo-fregeanismo
}

\author{
MARÍA DE PONTE*
}

\begin{abstract}
Neo-Fregeanism is a combination of two ideas: logicism, according to which arithmetic can be derived from logic plus definitions, and Platonism, according to which there are mathematical objects (which are abstract). NeoFregeans propose a new interpretation of Frege's principles of abstraction (mainly the so-called Hume's Principle) and of the role of reconceptualization and implicit definition for the introduction of numbers into our ontology. I analyze the ontological implications of neo-Fregeanism, not only for mathematics, but for abstract entities in general. After briefly introducing some of the main elements of neo-Fregeanism, I present two possible readings of its ontological implications and I argue that none of them gives the desired results.

Keywords: Platonism, logicism, reconceptualization, implicit definitions, priority thesis, nominalism, maximalism, relativism.
\end{abstract}

\begin{abstract}
Resumen: El neo-fregeanismo es una combinación de dos ideas: el logicismo, según el cual se puede derivar la aritmética de la lógica y definiciones, y el platonismo, según el cual hay objetos matemáticos (abstractos). Los neo-fregeanos proponen una interpretación nueva de los principios de abstracción Fregeanos (especialmente del llamado principio de Hume) y del papel de la reconceptualización y las definiciones implícitas para la introducción de los números en nuestra ontología. Analizo las implicaciones ontológicas del neo-fregeanismo, no sólo para las matemáticas, sino también para las entidades abstractas en general. Tras introducir brevemente los principales elementos del neo-fregeanismo, presento dos interpretaciones alternativas de estas implicaciones ontológicas y argumento que ninguna de ella aporta los resultados deseados. Palabras clave: Platonismo, logicismo, reconceptualización, definiciones implícitas, tesis de la prioridad, nominalismo, maximalismo, relativismo.
\end{abstract}

\section{Introduction}

The literature around neo-Fregeanism (NF, from now on) is very impressive. NeoFregeans promise a solution (or at least the beginnings of one) to some of the most debated philosophical issues in the twentieth century: mathematical existence, truth and knowledge. The goal of NF is, roughly, to combine two ideas: logicism, according to which arithmetic can be derived from logic plus definitions, and Platonism, according to which there are

Fecha de recepción: 01/03/2015. Fecha de aceptación: 29/03/2016.

* University of Seville. Profesora Ayudante Doctora. mdeponte@us.es Areas of Specialization: Philosophy of language, philosophy of mathematics, philosophy of time. Two recent publications: Kepa Korta \& María Ponte, 2015. “Tenses, dates and times” Research in Language. Vol. 12, 4: 301-317. María Ponte \& Margarita Vázquez, 2012. "Tense and temporal reference. Hybrid temporal logic" Logique \& Analyse, 220: 555-578.

Thanks to Manuel Liz, Kepa Korta, and Margarita Vázquez for their comments and suggestions on earlier drafts. This work was partially supported by the Spanish Ministry of Economy and Competitivity FFI201563719-P (MINECO/FEDER) and the Andalusian Government (P12-HUM-1216). 
mathematical objects (which are abstract). Most of the literature focuses on the possibility of reviving Frege's logicism, on the interpretation of Frege's principles of abstraction--mainly the so called Hume's Principle--and on the role of reconceptualization and implicit definition for the introduction of numbers into our ontology. Recently, however, some authors have attempted to analyze the ontological implications of NF, not only for mathematics, but for abstract objects in general. It is within these attempts that this paper belongs.

The ontological implications of both Frege's logicism and NF are far from clear. There are several interpretations of the ontological aspects of NF in the literature. It could be claimed that NF leads to "maximalism" (Eklund, 2006, Hawley, 2007); to "quietism" (MacBride, 2003) or to "quantifier variance" (Sider, 2007). ${ }^{1}$ These interpretations have important differences among them, but they all have in common a "deflationary" character. That is, according to all of them, NF entails some sort of deflationary or minimal ontology.

By deflationary ontology I mean here, roughly, that there are different interpretations of what does and does not exist and none of them is, in principle, better than the others. That is, deflationists believe that none of these possible interpretations is more "natural" than the others or, in Sider's terms, none "carves logical reality at its joints". This idea of NF as a kind of ontological deflationism (in which claims about the existence of entities are derived from the analysis of language) is best seen in a quote from Wright:

The irresistible metaphor is that pure abstract objects [...] are no more than shadows cast by the syntax of our discourse. And the aptness of the metaphor is enhanced by the reflection that shadows are, after their own fashion, real. (Wright, 1992, p. 181-2).

My plan for this paper is the following. I begin by introducing the main theses of NF, paying special attention to its defense of the priority of syntax over ontology and to its notion of reconceptualization. I then explore the existential commitments derivable from NF and its relation with the notion of analyticity. Afterwards I present two alternative interpretations of these commitments, a nominalist and a maximalist one. I claim that both of them are viable interpretations of NF and so that, being as it is an attempt to defend a realist position in mathematics, maximalism seems to be the best reading (perhaps the only possible reading) of NF. Maximalism, though, faces serious problems, which, I claim, NF cannot face unless it adopts some kind of relativization.

\section{Neo-Fregeanism, a brief introduction}

NF is to be considered mainly as a particular philosophy of mathematics, a proposal regarding mathematical existence, but also mathematical truth and mathematical knowledge. But it presupposes some substantive assumptions about the nature of reality and language in general. More specifically, it presupposes a particular view about the relation between language and reality, a view according to which "the structure of reality mirrors the contours of our speech" (MacBride, 2003, p. 108).

1 Sider does not defend quantifier variance himself; on the contrary, he devotes most of his efforts to combating it, but he does claim that it is the best interpretation for a defender of NF. 
As is well known, Frege's philosophy of mathematics was founded upon two basic elements: Platonism and logicism. ${ }^{2}$ It is also well known that his system failed when Russell proved it to be inconsistent. Shortly stated, NF accepts most of the philosophical framework underlying Frege's project, mainly its Platonism, its notion of analyticity of mathematics (i.e. its reduction to logic plus definitions) and the thesis that epistemological problems that affect platonist theses in mathematics can be solved through this reduction. But they only accept part of Frege's formal apparatus, thus avoiding Russell's paradox. ${ }^{3}$

Following the lead of Frege, NF argues that we gain knowledge of mathematical reality through the so called "abstraction principles", in particular the so-called "Hume's principle" (HP, from now on), which functions as an implicit definition of the concept of (cardinal) number. In other words, our knowledge of mathematical objects arises from principles that are analytic or true by meaning alone, and from our ability to derive mathematical truths from those analytic principles.

One central idea is the Fregean notion of the context principle, according to which only in the context of a proposition does a word mean anything. This, plus the idea, also Fregean, of the priority of syntax over ontology and the defense of the so called "abstraction principles" as an explanation of the way in which we reason, will be the core of the argument of NF. According to the neo-Fregeans, a proper understanding of the context principle and the priority thesis will not only prove that numbers exist, but it will also provide us with an explanation of our knowledge of them, so that it won't be necessary to postulate something like Gödel's idea of mathematical intuition to explain our access to them.

In order to apply all this to mathematical terms, and specifically (from now on) to number terms, it is necessary to determine the sense of the statements in which number terms occur. Besides, taking -as Platonists do- that number terms stand for self-sufficient objects, what is needed is an explanation of the sense of identity statements connecting terms with numbers. Very roughly, once we can assume that one such identity statement is true, and taken that number terms are singular terms, we will have to accept that they have a reference. Therefore, if number terms refer, number objects must exist.

According to NF, knowledge of the basic arithmetical laws (essentially, the DedekindPeano axioms), and hence of the existence of a range of objects which satisfy them -that is, knowledge of the concept of (cardinal) number- can be explained (a priori) by fixing the truth-conditions of identity statements between (canonical) singular terms and their instances; that is, by means of Hume's Principle, a second order abstraction principle according to which, informally:

(HP) The number of Fs is identical to the number of Gs if and only if there is a oneone correspondence between the Fs and the Gs

Formally:

$$
\text { (HP) } \forall F \forall G(n x: F x=n x: G x \leftrightarrow F 1-1 G)
$$

2 Frege (1884).

3 See Cook (2009) for an exposition of the differences and similarities between the original Fregean project and the NF one. 
Where "F1-1G" is (an abbreviation of) a second order formula expressing that there is a one-one correspondence between the object falling under the concept $\mathrm{F}$ and the objects falling under the concept G. ${ }^{4}$

Frege did not consider HP as a definition of the concept of number. Taken as a definition, HP faces the so-called "Caesar Problem", that is, it is incapable of stating whether Julius Caesar is a number or not (the definition is not applicable to sentences such as "the number of Fs = Julius Caesar"). For this reason, Frege introduced the notion of numbers as the extensions of concepts and with it the infamous basic law V which, as is well known, leads directly to Russell's paradox and thus to the collapse of Frege's logicism.

Now, it is well known that the Peano Axioms (including the second-order induction axiom) can be derived from HP plus suitable definitions of zero, successor and the like. This result is known as Frege's Theorem. It is the contention of NF that this theorem is enough for a proper definition of numbers. Further, it is NF's contention that such a definition is enough to ensure the existence of numbers.

Be that as it may, it is not my intention to get into these (otherwise amply discussed) technical issues; rather, I will just offer a brief description of the program and focus on the ontological implications of HP and NF. ${ }^{5}$

According to NF, HP is an implicit definition of -cardinal- number and that is what is needed to get both the concept of number and to derive the very existence of numbers. This raises many questions. To begin with, one might wonder: how can a definition determine the existence of the entities it attempts to define? Neo-Fregeans claim that HP is an implicit definition of the concept of cardinal number and that it is possible to derive the existence of cardinal numbers through the (truth of the) identity with equinumerosity. But, it might be objected, when we talk about equinumerosity we are not talking about numbers: equinumerosity does not require the existence of numbers. How can HP support their existence then? How can a definition introduce new objects?

\section{Implicit Definitions}

The answer to these questions requires understanding first the notion of "implicit definition" and its role in explaining mathematical knowledge. An implicit definition, roughly, is a definition in which the meaning of a term may be given by the assertion of statements containing it, by imposing some sort of constraint on the use of longer expressions containing the term in question. So if we consider, for example, a sentence \#f to be true, we can provide "f" with a meaning (a meaning that would make \#f true).

According to Wright and Hale, so long as we have asserted that concepts are one-one correspondent (so long as we have established Hume's Principle to be true) "there need to be no further problem about our knowledge of certain basic kinds of truths about numbers" (2002). Provided that we accept that Hume's Principle is an implicit definition of the concept of number we can know

4 The second order formula of equinumerosity can be formalized as: $\exists \mathrm{R} \forall \mathrm{x}(\mathrm{Fx} \rightarrow \exists \mathrm{y}(\mathrm{Gy} \wedge \forall \mathrm{z}(\mathrm{Rxz} \leftrightarrow \mathrm{z}=\mathrm{y})) \wedge$ $(\mathrm{Gx} \rightarrow \exists \mathrm{y}(\mathrm{Fy} \wedge \forall \mathrm{z}(\mathrm{Rzy} \rightarrow \mathrm{z}=\mathrm{y})))$.

5 Wright, 1983, is the locus classicus of NF. See also Hale and Wright, 2001, a compilation of their writings on this subject for the last decade or so. 
[S]tatements of [...] numerical identity to be true just by knowing the truth of the appropriate statements of [...] one-one correspondence among concepts. We can do so for the unremarkable reason that the truth conditions of the former are fixed by stipulation to coincide with those of the latter. (Hale and Wright, 2002)

There are many problems to be solved, however, before this can be a compelling account of a priori knowledge of mathematical statements. I focus here on one of them, in my opinion a very relevant one since it begs the very problem NF wanted to solve: to prove that there are abstract independent objects and that we have access to them.

According to implicit definitions, then, taking \#f to be true, and knowing the meaning of '\#', we can know the meaning of ' $\mathrm{f}$ ': the one which makes '\#f' true. But an obvious question arises here for, if we can state a priori that \#f is true only by knowing the meaning of \# and the syntactic structure of the sentence, then the meaning of ' $\mathrm{f}$ ' can't add anything substantial to the semantic value of the statement; the meaning of ' $\mathrm{f}$ ' must be, in this sense, conservative. But actually, in the case of HP the "number of F" asserts, on a platonist reading, something quite substantial, it implies an ontological commitment not present, prima facie, in the one-one correspondence.

This becomes clearer if we analyze the two sides of the biconditional separately:

The number of Fs is identical to the number of Gs

There is a one-one correspondence between the Fs and the Gs

Is easy to see that a) requires the existence of numbers to be considered as a literal truth $^{6}$ while b) does not. Wright answers this stating that even though speakers don't refer to numbers in b), their existence is implicit in the concept of equinumerosity. He claims that we can obtain knowledge of abstract objects (numbers or directions, in the other example used by him) through our knowledge of concrete ones (relation of equinumerosity or relation of parallelism between two lines).

Moreover, and this leads us to the point to be discussed here, he claims that we can infer the existence of the former from the existence of the latter, but how can this be possible? According to him, the existence of abstract objects such as numbers is conceptually necessary and follows logically from the existence of equinumerosity (as the existence of directions follows logically from the existence of parallel lines). And this is so, he claims, because HP is to be considered a "reconceptualization".

\section{Reconceptualization}

Basically, considering HP as a reconceptualization means claiming that the two sides of the biconditional have the same content, the difference being only in the way this content is conceptualized. Hence it is relatively easy to see how HP guarantees the existence of numbers. The idea is to go from the truth of the right-hand-side of the biconditional (there is a one-one correspondence between the Fs and the Gs) to the truth of the left-hand-side (the number of Fs is identical to the number of Gs).

6 Literal in contrast with fictional or metaphorical truths. NF requires singular terms to refer to "real" entities, and not fictional or imaginary ones. Further on, I specify how they claim that if a statement is determined to be true, following the established criteria, then it is "really" true. That is, literally true. 
Now, if both sides of the biconditional have the same content, numbers would have to be somehow present in talk of equinumerosity. But surely, one might object, this cannot be so, since the left-hand side quantifies over numbers and the right hand side doesn't. Against this, neo-Fregeans argue that, contrary to appearances, when we talk about equinumerosity we are implicitly assuming the existence of numbers (even though we are not quantifying over them and thus we are not making any reference to them).

This is a crucial, and problematic, aspect of NF. We have to be able to use concepts without knowing which entities fall under it, or at least, without knowing all the entities that fall under it. Wright establishes a useful distinction here; he claims that even though talk about equinumerosity implicitly entails a commitment to the existence of numbers, it does not entail reference to numbers. Using his example, talk about "aunt" implicitly entails a commitment to the existence of parent and a sister (irrespective of whether we know it or not), but it does not necessarily entail referring to any of those.

One aspect worth mentioning, for it will be relevant for our later discussion, is that by HP and other abstraction principles, and by the idea of reconceptualization, Neo-Fregeanists do not attempt to claim that numbers are introduced or created in some way. What is introduced is the concept of number, but the objects (numbers) were part of the underlying ontology presupposed by talk of equinumerosity. I think it might be helpful to quote Wright's exposition of the idea of reconceptualization (through the use of another example involving the concept of direction):

Consider again the abstraction for directions:

\section{$\mathrm{Da}=\mathrm{Db}$ if and only if $\mathrm{a} / / \mathrm{b}$}

The dilemma was that we either regard the left hand side simply as a definitional transcription of the right, and thereby forfeit the possibility of taking its syntax at face value, of treating it as a genuine identity statement linking genuine singular terms in existentially generalizable position; or we take the principle as a substantial claim, to the effect that certain abstract objects -directions- are associated with lines in the way it describes, in which case we have no right simply to lay the principle down as a definition. But the key to Frege's view is that the dilemma is a false one - it is the thought, roughly, that we have the option of laying down the Direction abstraction, of reconceptualizing, as it were, the type of state of affairs which is described on the right. [...] The concept of direction is thus so introduced that that two lines are parallel constitutes the identity of their directions. [...]

It is important to be clear that it would be a misrepresentation of this idea to view it as involving the notion that abstract objects are creations of the human mind, brought into being by a kind of stipulation. What is formed -created- by such an abstraction is rather a concept: the effect is merely to fix the truth-conditions of identity statements concerning a new kind of thing, and it is quite another question whether those truthconditions are ever realized. (Wright, 1997, pp. 277-278). 
So, NF claims that the existence of numbers (or directions) is already present (albeit implicitly) when we talk about equinumerosity relations (or parallelism). Hence neoFregeans do not want to defend the conditional assertion according to which "if numbers exist, then HP". Such conditional is not necessary, they claim, for numbers are part of the underlying ontology.

Now, even though the idea of reconceptualization is central for the NF program, it ultimately rests on a general conception of the relation between language and reality and therefore on the thesis of the priority of syntax over ontology and the context principle. These two principles (or theses) will also allow us to explore the possibilities of generalizing the NF proposal beyond the mathematical realm and to explore thus its ontological implications.

\section{The priority thesis}

According to Wright, the priority thesis not only asserts that there is a particular relation between reference and truth, i.e., that if certain statements (paradigmatically identity statements) are true then singular terms that occur in them (in the right way) do refer to determinate objects (through the context principle), and thus these objects exist. It also states that truth is prior to reference. That is, if, by ordinary criteria, a statement is true, then it is really true (beyond any reasonable doubt). Hence, if by ordinary criteria ${ }^{7}$ we establish the truth of a mathematical statement, we can establish that the singular terms occurring in it refer and, thus, the existence of mathematical entities (to which these terms refer) would be proved beyond any doubt. Wright, in one of his most quoted paragraphs, explains it so:

According to [the thesis of the priority of syntactic over ontological categories], the question whether a particular expression is a candidate to refer to an object is entirely a matter of the sort of syntactic role which it plays in whole sentences. If it plays that sort of role, then the truth of appropriate sentences in which it so features will be sufficient to confer on it an objectual reference; and questions concerning the character of its reference should then be addressed by philosophical reflection on the truth-conditions of sentences of the appropriate kind. If, therefore, certain expressions in a branch of our language function syntactically as singular terms, and descriptive and identity contexts containing them are true by ordinary criteria, there is no room for any ulterior failure of 'fit' between these contexts and the structure of the states of affairs which make them true. So there can be no philosophical science of ontology, no well-founded attempt to see past our categories of expression and glimpse the way in which the world is truly furnished. (Wright, 1983, pp. 51-52)

7 What is meant by ordinary criteria is, precisely, one of the most problematic issues of the proposal. We'll try to see the alternatives later, when we talk about the possible limitations to NF's overinflated ontology. Field, 1989, expresses the difference between a trivial reading of the context principle and the more radical one by differentiating between a "weak" and a "strong" priority thesis. He then argues that it is not possible to develop a proper account of what is meant by "ordinary criteria" and thus, that the strong priority thesis (needed to ensure Platonism) is not viable. 
So, NF reverses the usual, realist, way of understanding the relation between language and reality, in which it is generally assumed that the nature of reality is fixed independently of language. Neo-Fregeans believe that language and reality are very closely related; so closely in fact that, as MacBride puts it, "the structure of reality inevitably mirrors the contours of our language" (2003, p. 108).

\section{Existential commitments and analyticity}

So far so good, but it is far from clear how the notion of implicit definition, the priority thesis and the subsequent notion of reconceptualization could bear the weight of the existential commitments required by platonists. I present two possible interpretations of NF. One leads to triviality, making the claim that numbers exist superfluous. The second leads to an overgeneralization, entailing the existence of counterintuitive, exceptional and even incompatible entities. Ultimately, I claim, the only way available for NF is to accept the introduction of a certain level of relativization.

This should not be a surprise - it follows directly from some basic aspects of the neoFregeans' philosophical framework, i.e., from their belief in the preeminence of language over ontology. But it would certainly be a problem for them. It would mean, that their main goal, defending and justifying Platonism, accounting for mathematical knowledge and mathematical truth, has failed.

An apparent problem with NF, we hinted, was understanding how it was possible to logically derive the existence of certain kind of entities from the existence of some other -completely different- entities. That is, how to make sense of the claim that numbers are independent objects, completely different from equinumerosity and yet their existence and properties follow logically from the existence and properties of equinumerous objects.

Actually, nothing would prevent constructing the identity in nominalistic terms. Or, more precisely, a nominalist reading of the meaning of "the number of $F$ " will not change the truth-value of the whole. It will not make it false, but only "fictionally" true. The "number of F" could be read as a singular term syntactically speaking, but functioning semantically like fictional terms such as "Hamlet", and this will not change the semantic value of the identity. So, what prevents us for making this nominalist reading of the identity, apart from some independent considerations about the convenience of not doing so? That is, the choice between a platonist or a nominalist reading does not seem to be determined by anything contained in NF, failing thus in one of its main goals: justifying and accounting for Platonism.

This ontological neutrality follows from the required analyticity of HP and of the abstraction principles in general. The problem is explaining how an analytic principle, such as HP, can guarantee the existential commitment required by the platonists. This is a doubt similar to the one raised by Boolos in his article "Is Hume's principle analytic?" HP possesses too much content to be analytic. Boolos suggests that there is a clear analogy between HP and "the present king of France is royal" in that "we have no analytic guarantee that for every value of " $F$ ", there is an object that the open definite singular description "the number belonging 
to F" denotes" (1998, p. 306) ${ }^{8}$ In other words, there seems to be "no reason at all to believe that it is analytic that for every $\mathrm{F}$, there is such a (unique) object $\mathrm{x}$ ". (Boolos, 1998, p. 308). ${ }^{9}$

Platonists could argue that implicit definitions do indeed require existential commitment since, as we have seen, the context principle requires that number terms within it have a referent. But this is not straightforward. Following Hartry Field (1989) we could differentiate between weak and strong priority theses (priority of syntax). According to the weak priority thesis number terms function syntactically as singular terms and therefore also function semantically as such. This ensures that number terms can't be reduced to terms about oneone correspondence (it keeps the semantical independence of the former and so avoids what Field calls "ontological reductionism").

This weak thesis is strong enough to grant the viability of existential commitment of statements of the form:

$$
2+1=3
$$

The number of books in this room is greater than or equal to 3

But it doesn't rule out completely the possibility of denying it. It is not enough, in order to defend Platonism, to develop a way of stating that by Hume's Principle together with the context principle, we can infer that number terms refer and that number objects exist. What is needed is a way of asserting that it is necessarily true that numbers exist, that every question about the existence of numbers is "vacuous". And the weak priority thesis certainly does not grant this.

Consider a staunch nominalist. She could accept, in the light of the arguments given so far, that (2) is true and thus that the term " 3 ", being a singular term, implies an existential commitment. But that would not prevent her from arguing (as Field in fact does, or at least did) that (2) can and should be re-formulated so that " 3 " doesn't function as a singular term any more, but rather appears as part of a numerical quantifier. That is, (2) could, and perhaps should, be read as,

$2 *$. There are at least 3 books in the room,

which does not entail the existence of numbers or any other abstract entity.

Of course, the nominalist who re-formulates sentences this way will have to give reasons as to why we should prefer $\left(2^{*}\right)$ over (2) and show that we can make similar re-formulation for the relevant cases. But this is not the important point here. The relevant point is to notice that implicit definition plus context principle does not guarantee the existence of numbers. Or rather, that implicit definitions plus the context principle are compatible with a nominalist reading. If what we want is to justify our knowledge of mathematical entities and account for mathematical truth, we need to show that the existence of those objects is necessary; we need to prove, by implicit definition, that those objects exist. Otherwise it won't be possible to state, as NF does, that just by knowing the truth of statements about

8 Boolos also develops in this article what has been called "the bad company argument" according to which "there may be some analytic truths in the vicinity of HP with which it is being confused". More on this later.

9 Ibid, pp. 308. Recall that in this quote another problem is being mentioned: the problem of uniqueness. How can we know that the concept $\mathrm{F}$ denotes one, and only one, object $\mathrm{x}$ ? 
one-one correspondence we know the truth of statements about numbers (and hence that we have knowledge of numbers themselves through knowledge of equinumerosity).

So the weak priority thesis is not enough to assert, as Wright (1983) does, that it is "a preconception inbuilt into the syntax of our arithmetical language" that "4" is not only a singular term, but one which in fact denotes.

According to Wright, statements about equinumerosity entail existence commitments ${ }^{10}$ about numbers and so every doubt about the existence of numbers must be vacuous.

[I]t has to be the case that when it has been established, by the sort of syntactic criteria sketched, that a given class of terms are functioning as singular terms, and when it has been verified that certain appropriate sentences containing them are, by ordinary criteria, true, then it follows that those statements do genuinely refer. (Wright, 1983, p. 14).

But we have argued that the weak reading of the priority thesis doesn't entail that all doubts about the existence of numbers are vacuous. Platonists need something "stronger". The problem, of course, is establishing what more is needed and, above all, how to combine it with the analytic nature of HP and arithmetic. The question would rest, ultimately, on the definition of analyticity. A proper definition of analyticity would allegedly not only clarify what level of content can be introduced in order to derive the required existential commitments, it would also contribute to solving one of the most pressing problems affecting NF: the so-called "Bad company objection". We shall see this objection briefly in the next section and the relevance of the notion of analyticity to it, but I will not get into further details about this issue. Until an account of what a stronger priority thesis might possibly be, and how it might work respecting the boundaries imposed by analyticity, the nominalist interpretation remains a plausible one. The existence of numbers does not follow from HP (plus definitions). It is an independent presupposition. A presupposition that we might accept or not, in the light of other considerations, but that is not forced upon us by NF.

In other words, HP could be indeed considered as an analytic principle and so could play its role as a principle upon which derive the basic axioms of arithmetic, only if we read it as:

$$
\text { (HP*) If numbers exist } \rightarrow \forall F \forall G(n x: F x=n x: G x \leftrightarrow F 1-1 G)
$$

But this, as we already said, although it might have some interest for a definition of number properties, is ontologically trivial; it does not rule out the possibility of there being no numbers, and HP still being true.

10 Notice that Wright doesn't claim that statements about equinumerosity entail reference to numbers, but only existential commitments. This is an important difference. We could imagine some language, some model for arithmetic, in which we could state the basic rules of arithmetic without any use of numbers (we could imagine a society in which nobody has ever heard of numbers). It would be wrong to claim that people who used this language without number terms (because they don't know them) were referring nonetheless to numbers. But we could claim that by their use of this model of arithmetic they were making an existential commitment to numbers (using one-one correspondence terms, for example, they are implicitly stating the existence of numbers but they are not referring to numbers). 


\section{Linguistic approaches to ontology. Maximalism}

$\mathrm{NF}$ is not alone in deriving ontological conclusions from linguistic premises. This is a quite common view in analytic philosophy. Quine notoriously claimed something along these lines. ${ }^{11}$ According to him, and to what has been called the Quinean school, what there $i s$, is what our best theory of the world is ontologically committed to, or, in other words, what this theory quantifies over. In Quine's famous words "to be is to be the value of a variable".

Here too, we do not come to know what there is, and through this knowledge assert what should be our ontological commitments. Rather, we first establish what is our best theory of the world and then we look for the ontological commitments of this theory, by seeing what its statements quantify over. By knowing these ontological commitments, we come to know what there is.

Linguistic approaches, like NF and Quine's, share an important and controversial consequence: they all seem to lead to an overinflated ontology. This generous view about ontology has received different names, "maximalism", "absolutism" or "explosivism" among others. I use the term "maximalism," for it is the one commonly used in connection with NF. Very roughly, what maximalism claims is that everything that can exist does exist. In the area of philosophy of mathematics this view has important similarities with the "full-blooded Platonism" defended by Mark Balaguer (1998), according to which every mathematical object that can exist, in the sense of logical possibility, exists.

To see how NF leads to maximalism, I'll use the example developed by Matti Eklund (2006). ${ }^{12}$ According to this example, NF is committed to the existence of certain extraordinary objects called "incars": "would-be objects almost like cars except for the difference that they only exist when or in so far as they are inside garages" (Eklund, 2006, p.102). So, every time a car goes into a garage, a new entity comes into existence (incar) and it stops existing every time the car goes out of the garage. Notice that we are not talking of a new concept or of a new property of cars coming into existence: incars are supposed to be entities by themselves.

It is easy to see why NF would be committed to the existence of incars. According to them the only requirement for an entity to exist is being the referent of a singular term that appears in a true identity statement. Thus incars exist if there are true sentences containing "incar" in the right place.

Maximalism is certainly a difficult position to hold. Consider yet another potential problem, enunciated by Putnam (who uses the name explosivism instead of maximalism). Explosivism (as enunciated by Sosa) focuses on supervenient objects rather than on extraordinary ones; in the possibility of an indefinite number of entities coming out of each object and each event and existing "by themselves", that is, independently:

In recursion theory and hierarchy theory (...) we regularly take numbers as individuals, and functions of numbers, functions of functions, functions of functions of functions.... (...) as primitive. We do not take sets to be additional theories [as

11 See Quine (1948), Lowe (1995) and Eklund (2006).

12 Sosa (1999) develops a similar example to illustrate the position he calls explosivism or absolutism, using "snowdiscalls". Heck (2000) develops a similar argument against NF using the example of "Duds". 
the explosionist theory seems to require], but "identify" them with characteristic functions. In another branch of mathematics (set theory), we regularly take sets as primitive, and identify functions with sets of ordered pairs. I have never met a philosopher or a mathematician who thinks there is a "fact of the matter" as to which is right! Yet they can't be both right. (...) But if we go for the "exploding reality" approach, what do we do? Do we say there is a (possibly unknowable) "fact of the matter" as to whether sets are characteristic functions or functions are sets of ordered pairs? That, I must admit, seems crazy to me! (Putnam, 2004, p.244)

Maximalism is not the only option available in the literature for NF, though I do believe it is the most "natural" one. Ted Sider has recently defended an interpretation of NF in terms of quantifier variance. There is a very nice discussion between Sider and Katherine Hawley (2007) about which of these two views, maximalism or quantifier variance, is the most adequate interpretation of NF. I will not get into this debate here, for I argue that even though maximalism is the most straightforward interpretation, in the end it will face the dilemma of having to introduce some relativistic elements in the theory. Whether this relativism is better read as a kind of quantifier variance or whether it leads to some sort of quietism (as MacBride, 2003, claims) will remain as an open question. The main goal of the remainder of this paper is to show, first, that maximalism is indeed a coherent way to interpret NF and, second, that in order to serve the goals of NF, it will have to be restricted.

\section{NF as Maximalism}

In order for HP to be a proper explanation of the concept of number, NF needs to show that it is possible to understand a concept without knowing what objects fall under it. That is, that it is possible to grasp the meaning of the left-hand-side of the biconditional ("The number of Fs is identical to the number of Gs"), merely by grasping the meaning of the right hand side of the biconditional ("there is a 1-1 relation between the Fs and the Gs"). We should be able to understand a concept like the one expressed on the left hand side of $\mathrm{HP}$, to understand that the objects falling under it stand in a 1-1 relation, without knowing whether certain objects (numbers) fall under it.

As Hawley points out, maximalism fulfills this requirement. According to maximalism, all sorts of objects exist, objects we don't know about, objects that can be, in some cases, quite counterintuitive (like incars):

Presumably many of these things fall under concepts which we all understand (like being self-identical), so it must be possible to understand a concept without having a firm grasp on all the things which fall under it. Maximalism makes it compulsory to think of our understanding of concepts roughly as the neo-Fregeanists do, on pain of our not understanding even very familiar concepts. So, if we grant maximalism to the neo-Fregeanists the problem of impredicativity dissolves. (Hawley, 2007, p. 241)

Remember that the advocates of NF don't want to assert that through HP and reconceptualization we create numbers (or any other objects). Numbers already exist, 
and their existence is implicit in the concept of equinumerosity. Thus, it seems that NF would need to assume a very rich ontology, richer maybe that they'd like to admit. ${ }^{13}$ Maximalism makes it easier, up to a certain extent, to defend Platonism through HP and reconceptualization. But it also faces the so-called "Bad Company objection".

Actually, the Bad Company objection is one of the main obstacles, if not the main one, for NF. So it is not really an objection against maximalism per se. If we accept that HP is (conceptually) true, then it is so in virtue of its form, in virtue of its being an abstraction principle. But then all abstraction principles, that is, all principles of the form:

$$
\forall \mathrm{P} \forall \mathrm{Q}(\phi \mathrm{P}=\phi \mathrm{Q} \equiv \mathrm{Q} \wedge \mathrm{A})
$$

where $\boldsymbol{A}$ is the equivalent relations on entities of the type $\mathrm{P}, \mathrm{Q}$, and $\phi$ is a function from entities of that type to objects, are (conceptual) truths. But this is clearly false, for consider Frege's (in)famous basic law V:

The value-range of $F=$ the value-range of $G$ iff $F$ and $G$ are coextensive

which Russell's paradox proved to be inconsistent. In fact, Boolos (1990) proved that, even if we add a consistency restriction over abstraction principles, the problem remains. And he did so by introducing the so-called parity abstraction principle,

The parity of $\mathrm{F}=$ the parity of $\mathrm{G}$ iff $\mathrm{F}$ and $\mathrm{G}$ differ evenly (where two concepts differ evenly if an even number of things fall under one but not the other) (Eklund, 2006, p. 111).

which is consistent but can only be true in finite domains. The problem is thus that both principles, HP and parity, are consistent and satisfiable; but HP is only satisfiable in infinite domains and the parity principle in finite ones. Hence, they are not both co-satisfiable. NF still owes an explanation of what abstraction principles are acceptable, and what are not.

Anyhow, there is a huge amount of literature on the Bad Company objection, and the problem is still far from being solved (Hale and Wright, 2001, acknowledge it as one of the most pressing problems for NF). Our concern here is whether, and how, it affects maximalism, and whether maximalism can help in solving it.

Eklund claims, and I agree, that the Bad Company objection, under the light of maximalism, is clearly just a particular instance of a more general problem; the problem of incompatible objects. And so, abandoning abstraction principles will not help solving it. According to this problem,

Certain numbers exist, on a maximalist view. But then consider anti-numbers, where the concept of an anti-number is the concept of an abstract object whose existence

13 Really, they don't "presuppose" any ontology; the ontological commitments are imposed by syntactic considerations (through the priority thesis). I say a richer ontology than they'd admit because it is far from clear that actual NF (mainly articulated by Hale and Wright) would accept this maximalist interpretation of their view. 
both supervenes on anything one likes and rules out the existence of numbers. Antinumbers too would seem to satisfy maximalism's conditions for existence. But trivially numbers and anti-numbers cannot coexist. (Eklund, 2006, p. 112)

\section{Is there any alternative to maximalism for realists?}

The problem of incompatible objects is indeed a very serious one, and it doesn't seem to have an "easy" solution from the maximalist perspective. Actually it might be that the only way to solve it is through the acceptance of some kind of "conceptual relativity". Relativization is not foreign to NF, and at some points, some traces of it can be found in the writings of both Hale and Wright.

Both in the case of incompatible objects and in the case of extraordinary ones, it seems that what we need is some sort of constraint on the criteria we use to assert that certain identity statements are true. Recall that the priority thesis states that when, by ordinary criteria, a statement is true, it is really true (beyond any reasonable doubt). This idea of "ordinary criteria" is, I believe, the key notion here.

It could be claimed that, in the case of extraordinary objects, their counterintuitiveness is a reason to deny their existence. After all, it would be reasonable enough to consider as part of our "ordinary criteria" to reject statements that imply their existence. That is, it could be stated that it is part of our ordinary criteria to consider statements that refer to incars false. But this option faces two objections. On the one hand, the requirement of "intuitiveness" is way too vague to constitute the basis for deciding which (identity) statements are to be considered true and which false. Besides, the whole idea seems to go against NF's priority thesis, for we would be determining the truth of the statement on the basis of its ontological implications.

It seems clear that the constraint would have to be placed not on the ontological implications of the theory, but rather on language. That is, what is needed is a way to determine what identity statements are really true and which are not, without begging the question, without establishing beforehand what are the correct consequences to be derived from the distinction. One way of doing this is by focusing on language usages; that is, on the way we use the identity statements, and perhaps more importantly, the singular terms contained in them. This option would not be entirely within the spirit of NF, of course, since what they claim is that syntax comes prior to ontology, that taking into account only the syntactic structure of the statements we should be able to conclude whether it is true or false and hence whether the terms in it refer or not. But then again, maximalism itself is not the aimed ontology of neo-Fregeans. So it is worth considering whether introducing these pragmatic considerations might help, if not NF, at least maximalism.

Consider the case of a linguistic community in which talk of incars is perfectly consistent but in which talk of cars is highly objectionable; maybe, instead of a generic term for all cars in any situation as we have, they have different names depending on the location of the car, so that they have incars and outcars. Thus, following NF, names such as incars and outcars as used in this community would refer, even though in our community usage they do not. In other words, different uses of language determine different ontologies.

Actually, these kinds of cases are quite common in ordinary language. Consider for instance the difference in Spanish between "pez" and "pescado". Spanish speakers use different terms to 
denote fish, depending on whether it has been fished or not. That is, they use the word "pez" to denote all living or dead fishes which have not been fished (by humans) and "pescado" to all living or dead fish which have already been fished. Consequently, one would always eat "pescado", and never "pez" but, if snorkeling, one would always see "peces" and never "pescados".

It won't certainly be intuitive to derive from this that there are two different and independent entities, "peces" and "pescados"; that when a fish gets fished it ceases to exist and a new entity comes into existence and occupies its place (the "fished-fish" or "pescado"). But following maximalism, this is what we should claim, for we do not have a criteria to determine which of these uses leads to valid identity statements, i.e. true and thus with referring singular terms, and which to invalid identity statements, i.e. false and thus with non-referring singular terms.

Maximalism would of course make no distinction among these different uses, all of them are linked to one single and very rich underlying ontology. Differences in language use would be then just differences in ways of shaping or understating that underlying and amorphous bunch of existing entities. Flat or full-fledged relativism would on the contrary claim that each of these uses determines a concrete ontology since language and language uses determine what there is.

NF stands, as I see it, between these two positions. Because their aim is to defend Platonism, the most natural reading would be along the lines of maximalism. But maximalism faces the problem of incompatible entities, and, in the case of NF, it leads to the bad company objection. Thus, they need to put some restrictions on the ontology or, in their case, on the criteria to determine if an identity statement is really true and thus if the terms contained in it do indeed refer.

Again, neo-Fregeans do not claim that by stipulating the truth condition of the (identity) statements we create any objects. So they would reject the idea that the existence of incars/ outcars or peces/pescados depends on a determinate conceptual scheme or community usage. Rather, they would claim, what is introduced, or not introduced, are the concepts of incars/outcars and peces/pescados. This prevents their view from falling into flat relativism or quietism (as MacBride, 2003, defines it) but it also makes it even more difficult to conceive a possible restriction to maximalism to avoid not only extraordinary objects but, more importantly, incompatible ones.

Even though it is concepts that are introduced, NF entails that, when using them, we are implicitly "assuming" the existence of the entities in question. That is, when using the term "pescado", in a true identity statement, one would be implicitly entailing the existence of "pescado-entities", which are different from "pez-entities", since their concepts differ and the truth conditions of identity statements in which they appear might thus vary. So, once again, NF either accepts that both type of entities exist (maximalism) or draws a line in accordance with the different uses; finding a way to establish what uses are "correct" and "incorrect", without begging the very question they wanted to answer: which entities exist and which don't.

In any case, and to conclude, regardless of whether we introduce some sort of constraint to determine which identity statements are correct and which are not or whether we resign ourselves and go for a full-blooded maximalism, the most NF can show is that Platonism is a viable interpretation of HP and the abstraction principles in general. Or more precisely, they won't be able to claim that it is the best interpretation and certainly not, as they aim to, that it is the only viable one. 
NF can only satisfy those who are already convinced that abstract entities exist and that numbers are indeed abstract entities. If taken as an attempt to prove Platonism, I have claimed that NF fails, because its ontological implications are not the desired ones. A defense of Platonism can only come from considerations external to NF.

\section{References}

Balaguer, M. (1998) Platonism and Anti-Platonism in Mathematics.

Boolos, G. (1990) “The Standard Equality of Numbers", reprinted in Boolos (1998) Logic, Logic and Logic. Harvard University Press, pp.202-220.

Cook, R.T. (2009) "New waves on an Old Beach: Fregean Philosophy of Mathematics Today", in O. Bueno \& O. Linnebo (eds) (2009) New waves in philosophy of mathematics. Palgrave Macmillan, pp.13-34.

Eklund, M. (2006) "Neo-Fregean Ontology", Philosophical Perspectives, 20, Metaphysics: 95-121.

Field, H. (1989) Realism, Mathematics and Modality. Oxford: Blackwell.

Frege, G. (1884) Die Grundlagen der Arithmetik. W. Koebner, Breslau. English translation by J.L Austin (1950) The Foundations of Arithmetics. Oxford: Blackwell.

Hale, B. and Wright, C. (2001) The Reason's Proper Study Oxford: Oxford University Press.

Hale, B. and Wright, C. (2002) "Benacerraf's Dilemma Revisited", European Journal of Philosophy, 10: 101-29.

Hawley, K. (2007) “Neo-Fregeanism and Quantifier Variance”, Proceedings of the Aristotelian Society, Supplementary Volume 81 (1): 233-249.

Heck, R. (2000) "Syntactic Reductionism”, Philosophia Mathematica 8 (3): 124-149.

Lowe, E.J. (1995) "The Metaphysics of Abstract Objects", The Journal of Philosophy 92 (10): 509-520.

MacBride, F. (2003) "Speaking with Shadows: A Study of Neo-Logicism”, British Journal of Philosophy of Science 54: 103-163.

Putnam, H. (2004) "Sosa on Internal Realism and Conceptual Relativity", in Greco, J (ed) Ernest Sosa and His Critics. Oxford: Blackwell, pp. 233-248.

Quine, W.V. (1948) "On What There Is", Review of Metaphysics 2: 21-38.

Sider, T. (2007) "Neo-Fregeanism and Quantifier Variance", Proceedings of the Aristotelian Society, Supplementary Volume 81 (1): 201-232.

Sosa, E. (1999) "Existential Relativity” Midwest Studies in Philosophy 23 (1): 132-143.

Wright, C. (1983) Frege's Conception of Numbers as Objects. Aberdeen University Press.

Wright, C. (1997) “On the Philosophical Significance of Frege's Theorem”. Reprinted in Hale and Wright 2001, pp. 272-307. 